\title{
Cost-Effectiveness and Antimicrobial Resistance in Community-Acquired Pneumonia
}

\author{
Steven Simoens*
}

\author{
Research Centre for Pharmaceutical Care and Pharmaco-economics, Katholieke Universiteit Leuven, Onderwijs en \\ Navorsing 2 P.O. Box 521, Herestraat 49, 3000 Leuven, Belgium
}

Keywords: Community-acquired pneumonia, economic evaluation, cost-effectiveness, antibiotics, resistance.

\section{COMMUNITY-ACQUIRED PNEUMONIA}

Community-acquired pneumonia (CAP) covers those infections of the lung parenchyma that are not acquired in hospital or a long-term care facility. CAP is a common infectious disease, with annual incidence rates of 1.6 per 1,000 adults in Spain and 11.6 per 1,000 adults in Finland [1,2]. CAP is associated with significant morbidity and is the leading cause of death due to infection in developed countries [3, 4]. The economic burden of CAP is substantial: in the United States, CAP accounts each year for 10 million physician visits, and about 1 million hospitalizations at an estimated hospital cost of $\$ 9$ billion $[5,6]$.

\section{ANTIMICROBIAL TREATMENT}

Patients suffering from mild to moderate CAP are generally treated with oral antimicrobials in the community [7]. Hospitalisation may be required for elderly patients, patients who have underlying chronic illnesses or patients with more serious disease. In the majority of patients [4], antimicrobial treatment is empirical in that treatment is initiated in the absence of information about the causative pathogen involved in CAP and the antimicrobial susceptibility pattern of the isolated organism. The empirical approach is also the prevailing method of drug selection [8]. The treatment approach to CAP is challenging due to the expanding spectrum of causative pathogens, the rising prevalence of resistance to antimicrobial agents and the increasing pressure to reduce the length of hospitalization [9].

Various professional societies have published clinical guidelines to guide antimicrobial treatment of CAP [10,11]. These guidelines recommend a beta-lactam-based therapy for CAP as first choice. Moxifloxacin monotherapy is a useful alternative for outpatients with comorbid conditions, outpatients in whom infection with atypical pathogens (in particular Legionella spp.) needs to be taken into consideration, inpatients who do not require intensive care unit care, patients recently treated with other antibiotics, and patients

\footnotetext{
*Address correspondence to this author at the Research Centre for Pharmaceutical Care and Pharmaco-economics, Katholieke Universiteit Leuven. Onderwijs en Navorsing 2, Herestraat 49, P.O. Box 521, 3000 Leuven, Belgium; Tel: +32-(0)16-323465; Fax: +32-(0)16-323468;

E-mail: steven.simoens@pharm.kuleuven.be
}

with suspected 'high-level' drug-resistant Streptococcus pneumoniae.

\section{ANTIMICROBIAL RESISTANCE}

The guidelines of the European Respiratory Society also stated that the selection of antimicrobial needs to reflect local patterns of microbial resistance in addition to the severity of illness, the frequency of specific pathogens and drug safety profiles [10]. When antimicrobials first became available, changes in the susceptibility of pathogens were of little concern. However, inappropriate use of antimicrobials, (human-to-human) clonal spread of multi-drug resistant strains and the presence of co-morbidities have all contributed to the rise in antimicrobial resistance over the years. Antimicrobial resistance can have a substantial impact on outcomes and costs of treatment. For instance, there is evidence that CAP patients with pneumococcal resistance may be at greater risk of poor outcomes [12]. Also, if first-line treatment fails due to resistance, additional costs are incurred due to the need for second-line treatment or hospitalization, or both.

Fluoroquinolones are a class of antibiotics developed in the 1980s. Newer fluoroquinolones have increased activity against Gram-positive bacteria, including Streptococcus pneumoniae, and against atypical micro-organisms (Mycoplasma, Chlamydia and Legionella). Current resistance to fluoroquinolones is still low $(<1 \%)$ [13], but if fluoroquinolones become more widely used in the community for the treatment of CAP, resistance is expected to spread with the potential induction of cross-resistance even to the new fluoroquinolones. There is debate over the role of fluoroquinolones in treating CAP. On the one hand, as current resistance of Streptococcus pneumoniae to macrolides and tetracyclines is relatively high and rising over time in many countries [14], a case can be made for switching to antipneumococcal fluoroquinolones as an alternative to penicillins. On the other hand, it could be argued that the use of fluoroquinolones needs to be restricted in order to contain future resistance development and to safeguard the value of this class of antibiotics.

\section{ECONOMIC EVALUATION}

In a context of spiraling health care costs and limited resources, policy makers and health care payers are con- 
cerned about the costs of antimicrobial treatment in addition to its effectiveness. Pharmaco-economic evaluation is a technique that can be used to determine whether antimicrobial treatment of CAP adds sufficient value to justify its costs. An economic evaluation is defined as a comparative analysis of at least two health technologies in terms of both their costs and outcomes [15]. Evidence derived from economic evaluations is used to inform antimicrobial pricing/reimbursement decisions in many countries. Antibiotics that provide better value are rewarded by means of a more favourable price/reimbursement. The requirement for economic evaluation fits within an overall trend towards evidence-based decision making in healthcare [16].

\section{AIMS}

Recently, four economic evaluations have been published that investigated the value of antimicrobial treatment of CAP in Belgium, Canada, France, Spain and the United States [17-20]. The aim of this Letter is to describe these studies because they present the opportunity to examine the possible relationship between cost-effectiveness and antimicrobial resistance of Streptococcus pneumoniae in CAP. Indeed, each economic evaluation explored the impact of varying the local estimates of resistance levels on the cost-effectiveness of antimicrobials by means of extensive sensitivity analyses.

\section{COST-EFFECTIVENESS AND ANTIMICROBIAL RESISTANCE IN CAP}

\section{Study Design}

The four economic evaluations employed decisionanalytic models to evaluate the cost-effectiveness of empirical antimicrobial treatment of patients suffering from mildto-moderate CAP [17-20]. Design characteristics of these studies are summarized in Table 1. Treatment strategies in-

Table 1. The Value of Antimicrobial Treatment of Community-Acquired Pneumonia

\begin{tabular}{|c|c|c|c|c|}
\hline Studies & Martin (2007) (17) & Martin (2008) (18) & Moore (2008) (19) & Sabes-Figuera (2008) (20) \\
\hline Country & France, Germany, USA & Belgium & Canada & Spain \\
\hline Currency & Euro and US dollars (2006) & Euro (2006) & Canadian dollars (2006) & Euro (2004) \\
\hline Analysis & Cost-consequence analysis & Cost-consequence analysis & Cost-consequence analysis & Cost-consequence analysis \\
\hline Perspective & Third-party payer & Third-party payer & Third-party payer & Third-party payer \\
\hline Sample & $\begin{array}{l}\text { Patients with mild-to-moderate } \\
\text { community-acquired pneumonia }\end{array}$ & $\begin{array}{l}\text { Patients with mild-to-moderate } \\
\text { community-acquired pneumonia }\end{array}$ & $\begin{array}{l}\text { Patients with mild-to-moderate } \\
\text { community-acquired pneumonia }\end{array}$ & $\begin{array}{l}\text { Patients with community- } \\
\text { acquired pneumonia }\end{array}$ \\
\hline Study first-line treatment & Moxifloxacin & Moxifloxacin & Moxifloxacin & Moxifloxacin \\
\hline $\begin{array}{l}\text { Comparator first-line } \\
\text { treatments }\end{array}$ & $\begin{array}{l}\text { Clarithromycin, co-amoxiclav, } \\
\text { azithromycin, doxycycline, } \\
\text { roxithromycin, amoxicillin, } \\
\text { cefuroxime acetil }\end{array}$ & $\begin{array}{l}\text { Clarithromycin, co-amoxiclav, } \\
\text { cefuroxime acetil }\end{array}$ & Azithromycin & $\begin{array}{l}\text { Telithromycin, amoxicillin, } \\
\text { clarithromycin }\end{array}$ \\
\hline Study design & Model-based study & Model-based study & Model-based study & Model-based study \\
\hline Source clinical data & Literature, expert opinion & Literature, expert opinion & Literature, expert opinion & Literature, expert opinion \\
\hline Source economic data & Literature & Literature & Literature & Literature \\
\hline Cost measures & $\begin{array}{l}\text { Drugs, contacts with healthcare } \\
\text { professionals, hospitalisation }\end{array}$ & $\begin{array}{l}\text { Drugs, contacts with healthcare } \\
\text { professionals, hospitalisation }\end{array}$ & $\begin{array}{l}\text { Drugs, contacts with healthcare } \\
\text { professionals, hospitalisation }\end{array}$ & $\begin{array}{l}\text { Drugs, contacts with } \\
\text { healthcare professionals, } \\
\text { hospitalization }\end{array}$ \\
\hline Effectiveness measures & $\begin{array}{l}\text { First-line clinical failure avoided, } \\
\text { second-line treatment avoided, } \\
\text { hospitalization avoided }\end{array}$ & $\begin{array}{l}\text { First-line clinical failure } \\
\text { avoided, second-line treatment } \\
\text { avoided, hospitalization } \\
\text { avoided, deaths avoided }\end{array}$ & $\begin{array}{l}\text { First-line clinical failure avoided, } \\
\text { second-line failure avoided, } \\
\text { hospitalization avoided }\end{array}$ & $\begin{array}{l}\text { Number of patients without } \\
\text { complications, number of } \\
\text { patients hospitalized }\end{array}$ \\
\hline Results & $\begin{array}{l}\text { Moxifloxacin dominant for all } \\
\text { outcomes }\end{array}$ & $\begin{array}{l}\text { Moxifloxacin dominant } \\
\text { for all outcomes }\end{array}$ & $\begin{array}{l}\text { The incremental cost-effectiveness } \\
\text { ratio of moxifloxacin treatment as } \\
\text { compared with azithromycin was } \\
\text { CAN\$ } 96.04 \text { per first-line clinical } \\
\text { failure avoided, CAN\$ } 118.71 \text { per } \\
\text { second-line failure avoided and CAN\$ } \\
502.47 \text { per hospitalisation avoided. }\end{array}$ & $\begin{array}{l}\text { Moxifloxacin dominant for } \\
\text { all outcomes }\end{array}$ \\
\hline Sensitivity analysis & $\begin{array}{l}\text { Deterministic and probabilistic } \\
\text { sensitivity analysis }\end{array}$ & $\begin{array}{l}\text { Deterministic and probabilistic } \\
\text { sensitivity analysis }\end{array}$ & $\begin{array}{l}\text { Deterministic and probabilistic } \\
\text { sensitivity analysis }\end{array}$ & $\begin{array}{l}\text { Deterministic sensitivity } \\
\text { analysis }\end{array}$ \\
\hline Incremental analysis & Dominance & Dominance & Yes & Dominance \\
\hline
\end{tabular}


volved oral antimicrobials, were recommended by clinical practice guidelines and reflected prevailing treatment pathways in the countries studied. First-line treatment was initiated in the community, with failure resulting in secondline treatment in the community or hospitalization. As these economic evaluations were carried out from the perspective of the third-party payer, the analyses considered health care costs only and did not include costs due to productivity loss.

The base case analysis calculated incremental costeffectiveness ratios using the following equation:

$\operatorname{ICER}=\left(\mathrm{C}_{1}-\mathrm{C}_{0}\right) /\left(\mathrm{E}_{1}-\mathrm{E}_{0}\right)$

where $C_{1}$ is the cost of the intervention; $C_{0}$ is the cost of the alternative with which the intervention is compared; $\mathrm{E}_{1}$ and $\mathrm{E}_{0}$ are the respective health outcomes of intervention and comparator.

The first-line intervention was moxifloxacin in each economic evaluation. The comparator strategies were betalactams (e.g. co-amoxiclav, cefuroxime), macrolides (e.g. clarithromycin, azithromycin) or tetracyclines (e.g. doxycycline). Effectiveness was assessed in terms of the rate of first-line clinical failures, of second-line treatments required, of hospitalizations required, and of mortality. A strategy is said to dominate the comparator when it is both less expensive and more effective.

\section{Clinical Failure}

The economic evaluations were based on the premise that clinical failure can occur due to two main reasons: lack of response to treatment in patients with susceptible pathogens and failure due to the presence of antimicrobial-resistant pathogens.

The failure rate in susceptible pathogens was estimated on the basis of antimicrobial success rates from published clinical trials in CAP. Meta-analyses were not suitable for use in the models as they did not focus on the population of patients suffering from mild-to-moderate CAP. A wide range of efficacy data was found in the literature due to differences in trial design, treatment setting, patient population, duration of treatment, trial size, outcome measures used, etc. The estimates were based on those clinical trials that could be matched as far as possible to the patient population, causative pathogens, time horizon, dosage and outcome measures considered in the economic evaluations.

The failure rate in antimicrobial-resistant pathogens was estimated on the basis of data from published surveillance studies. The majority of samples considered in surveillance studies related to hospitalized patients. However, a recent study showed that the prevalence of resistant isolates in a hospitalized and community setting is similar for community-acquired pathogens [21], thus making it possible to generalize surveillance data to the community setting. Antimicrobial resistance data related to each country considered or were derived from published sources in the absence of country-specific data. The models considered resistance to various first-line antimicrobial treatments, including fluoroquinolones (e.g. moxifloxacin), beta-lactams (e.g. co-amoxiclav, cefuroxime), macrolides (e.g. clarithromycin, azithromycin) and tetracyclines (e.g. doxycycline). The models also made assumptions about clinical failure rates due to resistance for each CAP pathogen. There is no published literature documenting the link between resistance and clinical failure. Therefore, the calculations of failure rates were based on the opinion of clinical experts. The model developed for the United States was compared to empirical data on treatment failure and results were very comparable, thus validating assumptions [17].

The economic evaluations for France, Germany, the United States, and Canada accounted for multi-drug resistance in Streptococcus pneumoniae isolates, where isolates resistant to the first-line antimicrobial agent also demonstrate resistance to the second-line antimicrobial $[17,19]$. For instance, according to 1998-2000 data from the Alexander Project, resistance to more than five antimicrobial drug classes amounted to $11.7 \%$ in France [22]. Therefore, the models calculated resistance prevalences for second-line antimicrobial treatment of CAP adjusted for the presence of multi-drug resistance. Multi-drug resistance did not play a role in the Belgian model given that the four treatment strategies considered included either moxifloxacin or coamoxiclav, either first-line or second-line, and both treatments lacked any level of resistance for Streptococcus pneumoniae [18].

\section{Sensitivity Analysis}

As there is uncertainty surrounding local resistance rates, deterministic and probabilistic sensitivity analyses were carried out. One-way deterministic sensitivity analyses were conducted to ascertain the robustness of cost-effectiveness results by varying key input parameters over plausible ranges. To assess the impact of changes in resistance level, resistance rates for Streptococcus pneumoniae and Haemophilus influenzae were changed from $-50 \%$ to $+50 \%$ of base case rates for each of the antimicrobials considered.

Probabilistic sensitivity analyses based on a Monte Carlo simulation were performed. Such an analysis requires that a probability distribution is assigned to the resistance rate. The beta distribution was chosen for resistance rates. Spontaneous cure rates and clinical failure rates for resistant isolates were assumed to be distributed as uniform random variables. For each iteration, the simulation drew input parameters at random from their statistical distributions and calculated cost and effectiveness pairs. At the end of the iteration process, the joint statistical distribution for costs and effectiveness was represented as a cloud of points on the cost-effectiveness plane.

\section{Results}

The impact of antimicrobial resistance on costeffectiveness was investigated in two ways: first, resistance levels were varied in each economic evaluation by means of sensitivity analyses; second, cost-effectiveness results can be compared between economic evaluations (and thus between countries with different levels of resistance), although factors other than resistance may explain differences in cost- 
effectiveness results between economic evaluations (e.g. costs of care, treatment protocols).

The sensitivity analyses and the comparison between countries indicated that varying levels of antimicrobial resistance in CAP pathogens and multi-drug resistance in Streptococcus pneumoniae isolates affected costs and clinical outcomes of antimicrobial treatment [17-20]. However, costeffectiveness conclusions did not change: treatment of CAP with moxifloxacin was more effective and less expensive than other antimicrobial treatment strategies in Belgium, France, Germany, Spain and the United States.

In Canada, the deterministic sensitivity analysis showed that a $50 \%$ increase in fluoroquinolone resistance would raise the incremental cost-effectiveness ratio of moxifloxacin treatment as compared with azithromycin to CAN\$ 101.47 per first-line clinical failure avoided [19]. Canada has faced a steady increase in macrolide resistance in Streptococcus pneumoniae over time [23], and further increases in macrolide resistance rates cannot be ruled out. Increases in macrolide resistance would result in more favourable costeffectiveness ratios for treatment with moxifloxacin.

The probabilistic sensitivity analyses demonstrated that treatment of CAP with moxifloxacin was more effective and less expensive in nearly all scenarios [17-19]. For instance, in France, moxifloxacin had a probability of $100 \%$ and $99.8 \%$ of being more effective and less expensive than coamoxiclav and clarithromycin, respectively. In the United States, the probability that moxifloxacin was more effective and less expensive than co-amoxiclav, azithromycin and doxycycline was $100 \%, 99.8 \%$ and $99.8 \%$, respectively. In Germany, these probabilities amounted to $67.1 \%, 54.4 \%$ and $100 \%$ as compared to amoxicillin, roxithromycin and cefuroxime, respectively. Finally, moxifloxacin was more effective and less expensive than co-amoxiclav, cefuroxime and clarithromycin in $99.4 \%, 99.9 \%$ and $92.6 \%$ of cases, respectively, in Belgium.

\section{CONCLUSIONS}

Few economic evaluations have examined clinical outcomes and costs of empirical antimicrobial treatment of CAP in the community taking into account resistance. When resistance levels were varied in sensitivity analyses, the current body of evidence demonstrated that levels of antimicrobial resistance in CAP pathogens and multi-drug resistance in Streptococcus pneumoniae isolates had a minimal impact on costs and clinical outcomes of antimicrobial treatment. In nearly all scenarios, treatment of CAP with moxifloxacin is the most cost-effective option. At the moment, worldwide resistance of CAP pathogens to moxifloxacin is low [13], but continued vigilance with regard to the evolution of antimicrobial resistance and its impact on the cost-effectiveness of moxifloxacin and of other antimicrobials is indicated. For instance, the association between moxifloxacin use and the rate of extended-spectrum beta-lactamase (ESBL) resistance needs to be considered and followed up [24].

\section{CONFLICT OF INTEREST}

No sources of funding were used to assist in the preparation of this manuscript. The author has no conflicts of interest that are directly relevant to the content of this manuscript.

\section{REFERENCES}

[1] Almirall J, Bolibar I, Vidal J, et al. Epidemiology of communityacquired pneumonia in adults: a population-based study. Eur Respir J 2000; 15(4): 757-63.

[2] Jokinen C, Heiskanen L, Juvonen H, et al. Incidence of community-acquired pneumonia in the population of four municipalities in eastern Finland. Am J Epidemiol 1993; 137(9): 977-88.

[3] Anderson RN. Deaths: leading causes for 2000. Natl Vital Stat Rep 2002; 50(16): 1-85.

[4] Talwar A, Lee H, Fein A. Community-acquired pneumonia: what is relevant and what is not? Curr Opin Pulm Med 2007; 13(3): 17785 .

[5] Grossman RF, Rotschafer JC, Tan JS. Antimicrobial treatment of lower respiratory tract infections in the hospital setting. Am J Med 2005; 118(Suppl 7A): 29S-38S.

[6] Niederman MS, McCombs JS, Unger AN, Kumar A, Popovian R. The cost of treating community-acquired pneumonia. Clin Ther 1998; 20(4): 820-37.

[7] Aliyu ZY, Aliyu MH, McCormick K. Determinants for hospitalization in " low-risk" community acquired pneumonia. BMC Infect Dis 2003; 3: 11 .

[8] Kuti JL, Capitano B, Nicolau DP. Cost-effective approaches to the treatment of community-acquired pneumonia in the era of resistance. Pharmacoeconomics 2002; 20(8): 513-28.

[9] Carratala J, Martin-Herrero JE, Mykietiuk A, Garcia-Rey C. Clinical experience in the management of community-acquired pneumonia: lessons from the use of fluoroquinolones. Clin Microbiol Infect 2006; 12(Suppl 3): 2-11.

[10] Woodhead M, Blasi F, Ewig S, et al. Guidelines for the management of adult lower respiratory tract infections. Eur Respir J 2005; 26(6): 1138-80.

[11] Mandell LA, Wunderink RG, Anzueto A, et al. Infectious Diseases Society of America/American Thoracic Society consensus guidelines on the management of community-acquired pneumonia in adults. Clin Infect Dis 2007; 44(Suppl 2): S27-S72.

[12] Lynch JP, III, Zhanel GG. Streptococcus pneumoniae: does antimicrobial resistance matter? Semin Respir Crit Care Med 2009; 30(2): 210-38.

[13] Simoens S, Decramer M. A pharmacoeconomic review of the management of respiratory tract infections with moxifloxacin. Expert Opin Pharmacother 2008; 9(10): 1735-44.

[14] Simoens S, Verhaegen J, Laekeman G, Peetermans WE. Treating respiratory tract infections in ambulatory care in Belgium: fluoroquinolone consumption and resistance development. Int J Antimicrob Agents 2005; 26(1): 62-8.

[15] Drummond M, Sculpher MJ, Torrance GW, O'Brien BJ, Stoddart GL. Methods for the economic evaluation of health care programmes. 3 ed. Oxford: Oxford University Press 2005.

[16] Perleth M, Jakubowski E, Busse R. What is 'best practice' in health care? State of the art and perspectives in improving the effectiveness and efficiency of the European health care systems. Health Policy 2001 56(3): 235-50.

[17] Martin M, Quilici S, File T, Garau J, Kureishi A, Kubin M. Costeffectiveness of empirical prescribing of antimicrobials in community-acquired pneumonia in three countries in the presence of resistance. J Antimicrob Chemother 2007; 59(5): 977-89.

[18] Martin M, Moore L, Quilici S, Decramer M, Simoens S. A costeffectiveness analysis of antimicrobial treatment of communityacquired pneumonia taking into account resistance in Belgium. Curr Med Res Opin 2008; 24(3): 737-51.

[19] Moore L, Martin M, Quilici S. The cost-effectiveness of targeted prescribing of antimicrobials in Canada for community-acquired pneumonia in an era of antimicrobial resistance. Value Health 2008; 11: A271-A272.

[20] Sabes-Figuera R, Segu JL, Puig-Junoy J, Torres A. Influence of bacterial resistances on the efficiency of antibiotic treatments for community-acquired pneumonia. Eur J Health Econ 2008; 9(1): 23-32. 
[21] Gordon KA, Biedenbach DJ, Jones RN. Comparison of Streptococcus pneumoniae and Haemophilus influenzae susceptibilities from community-acquired respiratory tract infections and hospitalized patients with pneumonia: five-year results for the SENTRY Antimicrobial Surveillance Program. Diagn Microbiol Infect Dis 2003; 46(4): 285-9.

[22] Jacobs MR, Felmingham D, Appelbaum PC, Gruneberg RN. The Alexander Project 1998-2000: susceptibility of pathogens isolated from community-acquired respiratory tract infection to commonly used antimicrobial agents. J Antimicrob Chemother 2003; 52(2): 229-46.

[23] Green K, McGeer A, Plevneshi A, Canadian Bacterial Surveillance Network. Trends in antimicrobial resistance in S. pneumoniae, Canada, 1993-2007. Barcelona: Presentation at the $18^{\text {th }}$ European Congress of Clinical Microbiology and Infectious Diseases 2008.

[24] Jacobs E, Dalhoff A, Korfmann G. Susceptibility patterns of bacterial isolates from hospitalised patients with respiratory tract infections (MOXIAKTIV Study). Int J Antimicrob Agents 2009; 33(1): 52-7.

Received: June 15, 2010

Revised: August 17, 2010

Accepted: September 07, 2010

(C) Steven Simoens; Licensee Bentham Open.

This is an open access article licensed under the terms of the Creative Commons Attribution Non-Commercial License (http://creativecommons.org/licenses/ by-nc/3.0/) which permits unrestricted, non-commercial use, distribution and reproduction in any medium, provided the work is properly cited. 